11

\title{
Дефектная мода в СВЧ волноводных брэгговских структурах с металлическими штырями
}

\author{
(С) Д.А. Усанов, А.В. Скрипаль, В.Н. Посадский, В.С. Тяжлов, А.В. Байкин \\ Саратовский национальный исследовательский государственный университет им. Н.Г. Чернышевского, \\ 410012 Саратов, Россия \\ e-mail: skripala_v@info.sgu.ru
}

Поступило в Редакцию 11 января 2019 г.

В окончательной редакции 19 марта 2019 г.

Принято к публикации 27 марта 2019 г.

Использование волноводной брэгговской структуры, содержащей цилиндрические штыри, расположенные на равном расстоянии друг от друга и гальванически связанные с одной из широких стенок волновода, позволило реализовать амплитудно-частотные характеристики, характеризующиеся наличием запрещенной зоны. Представлены результаты экспериментального исследования и расчета характеристик дефектной моды СВЧ фотонного кристалла со штыревым элементом в качестве дефекта с помещенной в его емкостной зазор $n-i-p-i-n$-структурой с регулируемой проводимостью. На частоте дефектной моды получено регулируемое отражение СВЧ-сигнала с динамическим диапазоном более $50 \mathrm{~dB}$.

Ключевые слова: СВЧ брэгговские структуры, $n-i-p-i-n$-структуры.

DOI: 10.21883/JTF.2019.10.48180.6-19

\section{Введение}

СВЧ периодические структуры, называемые СВЧ брэгговскими структурами или СВЧ фотонными кристаллами, привлекают интерес исследователей в связи с перспективой создания устройств с уникальными характеристиками в СВЧ диапазоне: измерительных устройств, согласованных нагрузок, различного типа фильтров и других [1-8].

В качестве периодических элементов в них различными авторами использовались, в частности, диэлектрические слои, отрезки микрополосковых линий с различной шириной микрополоска, металлические диафрагмы [9-11].

Нарушение периодичности в таких структурах может приводить к появлению так называемой дефектной моды, имеющей резонансный характер, часто по аналогии с физикой полупроводников, называемой примесной модой $[12,13]$.

Штыревые структуры представляют интерес в связи с их широким применением в СВЧ-технике в качестве держателей полупроводниковых элементов, располагаемых в емкостном зазоре штыря [14,15]. Использование штыря в качестве дефекта СВЧ фотонного кристалла открывает перспективу получения характеристик, недостижимых с помощью одиночного элемента.

Исследование характеристик дефектной моды СВЧ фотонного кристалла со штыревым элементом в качестве дефекта и возможности управления этими характеристиками внешним электрическим сигналом составляло цель настоящей работы.

Как известно, СВЧ фотонные кристаллы обладают чрезвычайно высокой отражательной способностью в пределах полосы запирания (,запрещенной зоны“).
Использование в качестве дефектного элемента СВЧ фотонного кристалла штыревого держателя с помещенной в его емкостной зазор структуры с регулируемой проводимостью может привести к достижению регулирования его характеристиками в широких пределах внешним электрическим сигналом.

\section{1. Модель СВЧ фотонного кристалла на основе волновода с металлическими штыревыми элементами}

В качестве СВЧ фотонного кристалла (рис. 1) рассматривался волновод трехсантиметрового диапазона (позиция 1 рис. 1) с брэгговской структурой, выполненной в виде периодически расположенных металлических штырей (позиция 4 рис. 1).

Схема расположения штырей с зазорами представлена на рис. 2. Штыри (позиция 1 рис. 2) располагались по центру широкой стенки волновода (позиция 2 рис. 2) на расстоянии $L=12 \mathrm{~mm}$ друг от друга. Диаметр центрального штыря был равен $1 \mathrm{~mm}$, диаметр остальных $2 \mathrm{~mm}$. Продольный размер системы из пяти штырей составил $50 \mathrm{~mm}$. Величина зазоров (позиция 3 рис. 2) между крайними штырями и одной и той же широкой стенкой волновода составляла $0.2 \mathrm{~mm}$, величина зазоров между вторым и четвертым штырями и противоположной широкой стенкой волновода составляла $0.59 \mathrm{~mm}$.

В качестве центрального штыря выбирался штырь, гальванически соединенный с обеими противоположными широкими стенками волновода и имеющий в центре разрыв величиной $1 \mathrm{~mm}$. Для управления характеристиками СВЧ фотонного кристалла использовался 


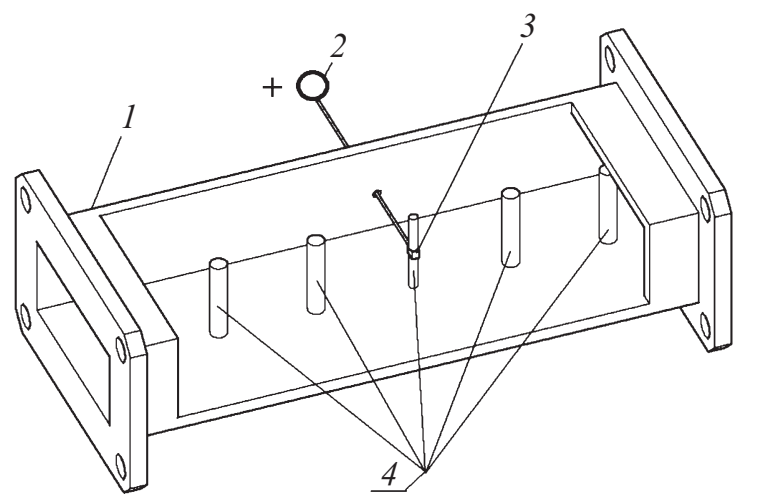

Рис. 1. СВЧ фотонный кристалл в виде волноводной штыревой системы с переключательным диодом на основе $n-i-p-i-n$-структуры: 1 - отрезок волновода сечением $23 \times 10 \mathrm{~mm}, 2-$ положительный полюс источника питания, $3-n-i-p-i-n$-структура, $4-$ штыри.

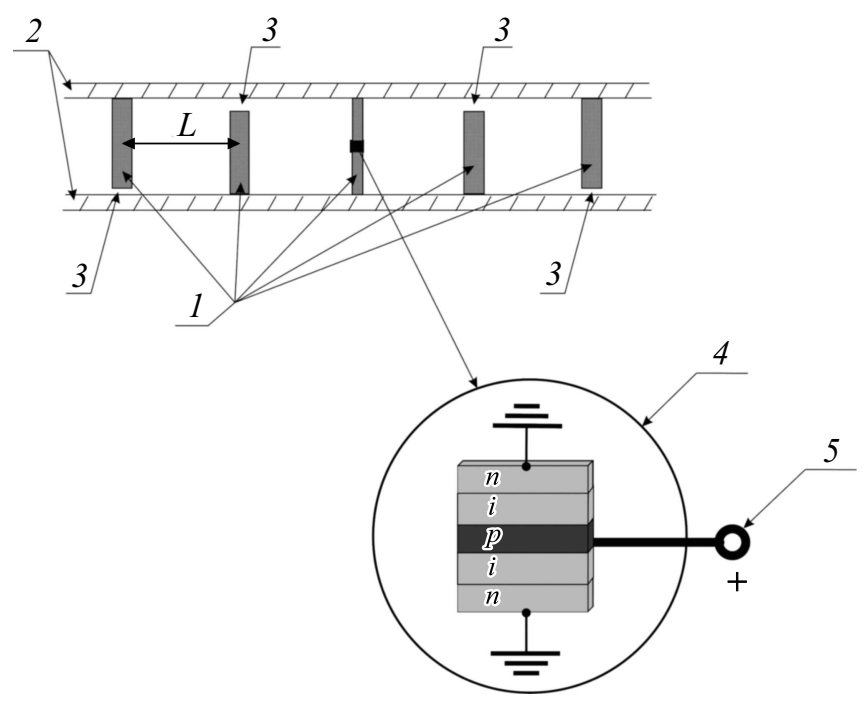

Рис. 2. Схема расположения штырей с зазорами: 1 - штыри, 2 - широкие стенки волновода, 3 - зазоры, $4-n-i-p-i-n$-структура, $5-$ положительный полюс источника питания.

кремниевый переключательный диод 2А505А на основе $n-i-p-i-n$-структуры, который располагался в разрыве центрального штыря (позиция 3 рис. 1 и позиция 4 на вставке к рис. 2).

На основе численного моделирования с использованием метода конечных элементов в программе ANSYS HFSS исследовались амплитудно-частотные характеристики коэффициентов отражения фотонного кристалла при различной удельной электропроводности $i$-слоя $n-i-p-i-n$-структуры. Предполагалось, что при прямом смещении удельная электропроводность $\sigma$ данного элемента изменялась в диапазоне от 0 до $10^{3} \mathrm{~S} / \mathrm{m}$. Такое изменение величины удельной электропроводности $\sigma$, обусловленное обогащением $i$-областей инжектированными носителями заряда, соответствует величине про- текающего тока в диапазоне от 0 до $300 \mathrm{~mA}$ с использованием $n-i-p-i-n$-структуры типа 2А505А.

Как следует из результатов проведенного нами численного расчета, на АЧХ СВЧ фотонного кристалла в виде периодической структуры для случая, когда штыревой центральный элемент уменьшенного диаметра не имеет разрыва и замкнут на обе противоположные широкие стенки волновода, в спектре пропускания возникает широкая запрещенная зона (от 8 до $12.1 \mathrm{GHz}$ ). Отсутствие дефектной моды в запрещенной зоне свидетельствует о незначительности влияния такого нарушения периодичности структуры на распространение СВЧ-волны в созданном СВЧ фотонном кристалле с выбранными параметрами, содержащем остальные цилиндрические штыри одинакового диаметра и расположенные на равном расстоянии друг от друга.

Результаты расчета частотной зависимости коэффициента отражения $S_{11}$ СВЧ фотонного кристалла при различной удельной электропроводности $i$-слоя $n-i-p-i-n$-структуры представлены на рис. 3 .

При отсутствии напряжения смещения $n-i-p-i-n$ структура, являющаяся элементом нарушения фотонного кристалла, совместно с элементами центрального металлического штыря может быть приближенно представлена в виде последовательного $R-L-C$-контура, где $R$ - сопротивление потерь в сильнолегированных

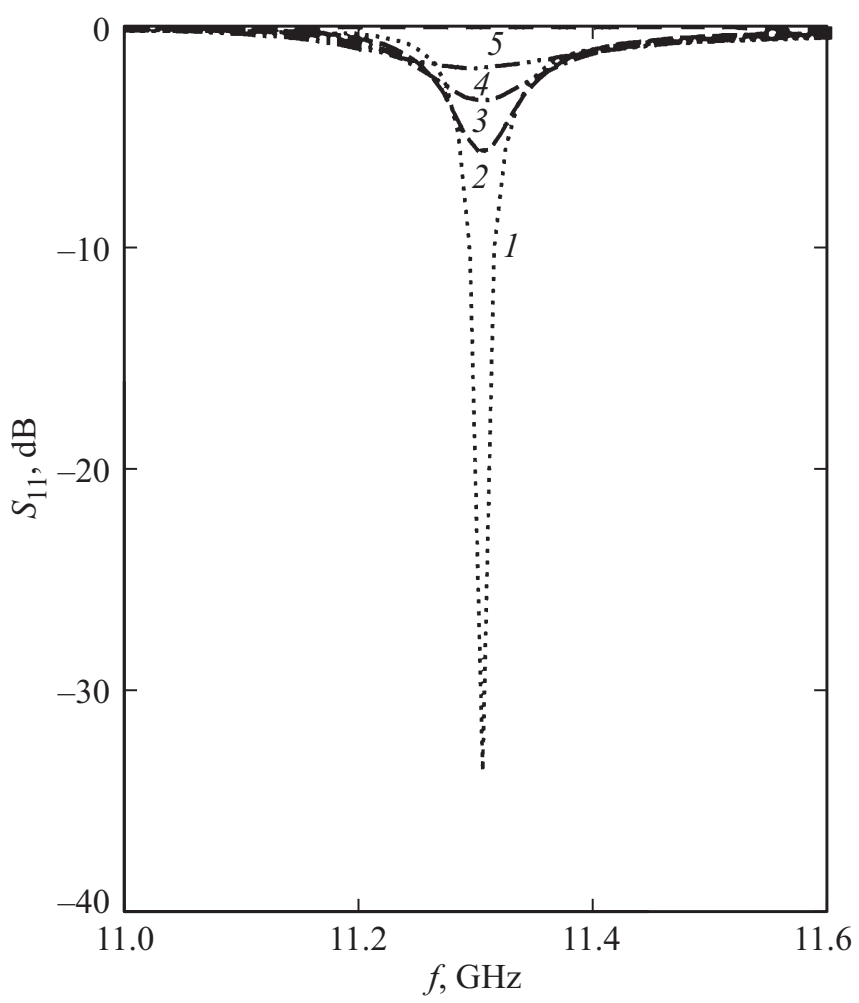

Рис. 3. Расчетные частотные зависимости коэффициента отражения $S_{11}$ электрически управляемого волноводного фотонного кристалла на основе штыревой системы при различной удельной электропроводности $i$-слоя $n-i-p-i-n$-структуры $\sigma, \mathrm{S} / \mathrm{m}: 1-0,2-1.0,3-2.0,4-5.0,5-100.0$. 
областях, омических контактах и выводах $n-i-p-i-n$ структуры; $C-$ емкость $i$-слоя; $L-$ индуктивность элементов центрального металлического штыря.

Приведенная на рис. 3 АЧХ (кривая 1) для этого режима свидетельствует о том, что на частоте $11.305 \mathrm{GHz}$ в запрещенной зоне фотонного кристалла возникает ярко выраженная дефектная мода, характеризующаяся коэффициентом отражения, равным $-33.3 \mathrm{~dB}$.

Увеличение удельной электропроводности $i$-слоя $n-i-p-i-n$-структуры приводит к увеличению коэффициента отражения на частоте дефектной моды.

При достижении удельной электропроводности $i$-областей $n-i-p-i-n$-структуры значений, больших $10^{2} \mathrm{~S} / \mathrm{m}$, сопротивление $n-i-p-i-n$-структуры уменьшается до нескольких единиц $\Omega$, что приводит к фактическому „исчезновению“ разрыва центрального штыря, и величина коэффициента отражения на частоте дефектной моды достигает величины меньшей $-0.1 \mathrm{~dB}$, т. е. дефектная мода в запрещенной зоне исчезает.

\section{2. Результаты эксперимента}

Экспериментально исследовался СВЧ фотонный кристалл трехсантиметрового диапазона длин волн (размеры поперечного сечения волновода $23 \times 10 \mathrm{~mm}$ ), созданный в соответствии с описанной выше моделью. $P$-область $n-i-p-i-n$-структуры гальванически соединялась через отверстие в узкой стенке волновода с положительным полюсом источника питания (позиция 2 рис. 1).

Частотные зависимости коэффициентов отражения $S_{11}$ СВЧ фотонного кристалла измерялись с помощью векторного анализатора цепей Agilent Microwave Network Analyzer N5242A PNA-X. На амплитудночастотной характеристике СВЧ фотонного кристалла в виде периодической структуры со сплошным штыревым центральным элементом, замкнутым на обе противоположные широкие стенки волновода, наблюдалась широкая запрещенная зона от 8 до $12.23 \mathrm{GHz}$.

При отсутствии управляющего тока, протекающего через переключательный диод $2 \mathrm{~A} 505 \mathrm{~A}$, центральный штырь уменьшенного до $1 \mathrm{~mm}$ диаметра, в разрыве которого размещен переключательный диод 2А $505 \mathrm{~A}$, выступает в качестве нарушения периодичности СВЧ фотонного кристалла на штыревых элементах.

Результаты эксперимента при отсутствии управляющего тока, протекающего через переключательный диод 2А 505A, хорошо согласуются по частоте $(11.323 \mathrm{GHz})$, на которой в запрещенной зоне СВЧ фотонного кристалла возникает ярко выраженная дефектная мода. Измеренный коэффициент отражения на этой частоте равен $-51 \mathrm{~dB}$ (кривая 1 рис. 4 ), что существенно превышает расчетное значение.

При увеличении управляющего тока, протекающего через переключательный диод $2 \mathrm{~A} 505 \mathrm{~A}$, происходит

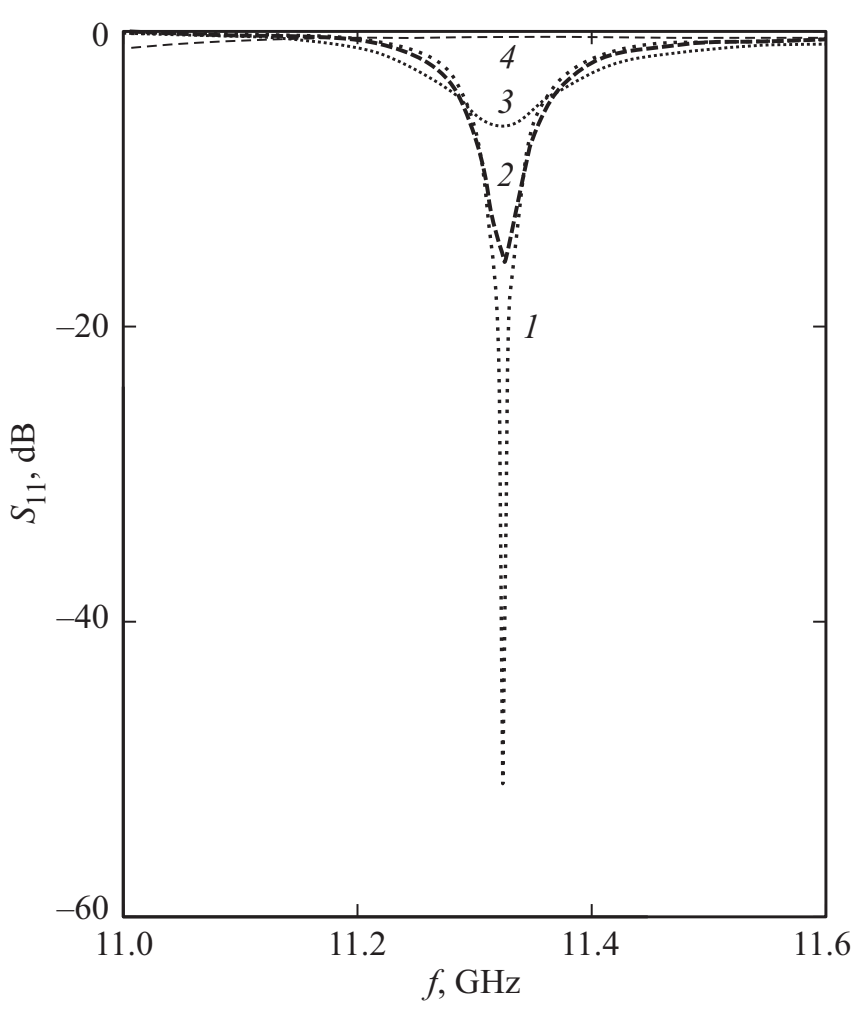

Рис. 4. Экспериментальные частотные зависимости коэффициента отражения $S_{11}$ электрически управляемого волноводного фотонного кристалла на основе штыревой системы при различных значениях управляющего тока $I, \mathrm{~mA}: 1-0.0,2-$ $0.7,3-9.0,4-120.0$.

монотонное увеличение коэффициента отражения СВЧ фотонного кристалла на частоте дефектной моды.

При достижении величины управляющего тока, равной $120 \mathrm{~mA}$, сопротивление $i$-области переключательного диода $2 \mathrm{~A} 505 \mathrm{~A}$ уменьшается до единиц $\Omega$ и величина коэффициента отражения на частоте дефектной моды достигает значения меньшего $-0.3 \mathrm{~dB}$, т.е. дефектная мода, как это следовало из результатов расчета, в запрещенной зоне практически исчезает.

Сравнение результатов расчета и экспериментальных результатов, полученных при практической реализации устройства, свидетельствует об их хорошем качественном соответствии.

Некоторое количественное несовпадение, выражающееся в небольшом различии частоты дефектной моды и динамического диапазона изменения коэффициента отражения на частоте дефектной моды при вариации уровня инжекции неравновесных носителей заряда в $i$-области $n-i-p-i-n$-структуры, может быть связано c ограниченностью модели, описывающей взаимодействие электромагнитного излучения с полупроводниковой $n-i-p-i-n$-структурой с использованием программы ANSYS HFSS, удельная эффективная электропроводность $\sigma_{\text {eff }}$ которой определяется как средняя величина удельной электропроводности полупроводниковой 
структуры $\sigma(x)$ и вычисляется с учетом координатной зависимости распределения неравновесных носителей заряда $p(x)$ в $i$-области с помощью выражения $[16,17]$

$$
\begin{aligned}
\sigma_{\mathrm{eff}} & =\frac{1}{i_{i}} \int_{0}^{l_{i}} \sigma(x) d x \\
& =q\left(\mu_{n} n_{0}+\mu_{p} p_{0}+\mu_{p} \frac{b+1}{l_{i}} \int_{0}^{l_{i}} p(x) d x\right) .
\end{aligned}
$$

где $\mu_{n}, \mu_{p}$ - подвижность электронов и дырок, $n_{0}, p_{0}-$ равновесная концентрация электронов и дырок в $i$-области, $l_{i}$ - длина $i$-области, $b=\mu_{n} / \mu_{p}$.

Следует отметить, что в случае учета зависимости коэффициентов диффузии электронов и дырок от напряженности электрического поля при высоком уровне инжекции неравновесных носителей заряда в $i$-области $n-i-p-i-n$-структуры может быть получена немонотонная зависимость распределения концентрации свободных носителей заряда $p(x)$ вдоль $n-i-p-i-n$ структуры, т.е. наблюдаются так называемые пространственные осцилляции плотности заряда в кремниевом $p-i-n$-диоде [18].

В этом случае удельная эффективная электропроводность $n-i-p-i-n$-структуры должна рассчитываться с использованием выражения (1) с учетом немонотонной зависимости $p(x)$.

\section{Заключение}

Таким образом, использование волноводной системы, содержащей цилиндрические штыри, расположенные на равном расстоянии друг от друга и гальванически связанные с одной из широких стенок волновода, позволило реализовать амплитудно-частотные характеристики, характеризующиеся наличием запрещенной зоны.

Для управления характеристиками фотонного кристалла использовался вводимый в фотонный кристалл элемент (полупроводниковая диодная $n-i-p-i-n$ структура с электрически управляемой проводимостью), нарушающий его периодичность, свойствами которого можно управлять внешним сигналом.

Как следует из результатов расчета и эксперимента, использование брэгговской структуры на основе штыревой системы в прямоугольном волноводе позволяет создать СВЧ фотонный кристалл, динамический диапазон изменения коэффициента отражения которого при изменении управляющего тока, протекающего через единственный переключательный диод $2 \mathrm{~A} 505 \mathrm{~A}$ от 0 до $120 \mathrm{~mA}$ достигает $51 \mathrm{~dB}$, при этом линейный размер фотонного кристалла составил $50 \mathrm{~mm}$. Характеристик такого уровня ранее не удавалось достичь с помощью известных типов СВЧ фотонных кристаллов.

Отметим, что использование в ближнеполевом СВЧ микроскопе [19] генератора, работающего в режиме модуляции, реализуемой с помощью предложенного устройства, открывает возможность расширения диапазона измеряемых параметров исследуемых материалов и структур и повышения точности измерений таким микроскопом.

\section{Финансирование работы}

Работа выполнена при финансовой поддержке Министерства образования и науки РФ (государственное задание № 8.7628.2017/8.9).

\section{Конфликт интересов}

Авторы заявляют, что у них нет конфликта интересов.

\section{Список литературы}

[1] Усанов Д.А., Никитов С.А., Скрипаль А.В., Пономарев Д.В. Одномерные СВЧ фотонные кристаллы. Новые области применения. М.: Физматлит, 2018. 184 с. ISBN 978-5-9221-1770-8

[2] Беляев Б.А., Волошин А.С., Шабанов В.Ф. // ДАН. 2005. T. 400. № 2. C. 181-185. [Belyaev B.A., Voloshin A.S., Shabanov V.F. // Dokl. Phys. 2005. Vol. 400. N 1-3. P. $7-$ 11. DOI: $10.1134 / 1.1862365]$

[3] Fernandes H.C.C., Medeiros J.L.G., Junior I.M.A., Brito D.B. // PIERS Online. 2007. Vol. 3. N 5. P. 689-694. DOI: $10.2529 /$ PIERS060901105337

[4] Ozbay E., Temelkuran B., Bayindir M. // Progr. Electromagn. Res. 2003. Vol. 41. P. 185-209. DOI: 10.2528/PIER02010808

[5] Gomez A., Vegas A., Solano M.A., Lakhtakia A. // Electromagnetics. 2005. Vol. 25. N 5. P. 437-460. DOI: $10.1080 / 02726340590957443$

[6] Saib A., Huynen I. // Electromagnetics. 2006. Vol. 26. N 3/4. P. 261-277. DOI: $10.1080 / 02726340600570336$

[7] Вендик И.Б., Вендик О.Г. // ЖТФ. 2013. Т. 83. Вып. 1. С. 3 28. [Vendik I.B., Vendik O.G. // Tech. Phys. 2013. Vol. 58. N 1. P. 1-24. DOI: 10.1134/S1063784213010234]

[8] Mollah Md. Nurunnabi, Karmakar Nemai C., Fu Jeffrey S. // Int. J. Electron. Commun. (AEU). 2008. Vol. 62. P. 717-724. DOI: 10.1016/j.aeue.2006.10.007

[9] Гуляев Ю.В., Никитов С.А., Усанов Д.А., Скрипаль А.В., Посадский В.Н., Тяжллов В.С., Байкин А.В. // ДАН. 2014. T. 458. № 4. C. 406-409. [Gulyaev Yu.V., Nikitov S.A., Usanov D.A., Skripal A.V., Posadskii V.N., Tiazhlov V.S., Baykin A.V. // Dokl. Phys. 2014. T. 59. N 10. C. 437-440. DOI: $10.1134 / \mathrm{S} 1028335814100024]$

[10] Усанов Д.А., Скрипаль А.В., Абрамов А.В., Боголюбов А.С., Куликов М.Ю. // Изв. вузов. Электроника. 2008. № 5. C. 25-32.

[11] Усанов Д.А., Никитов С.А., Скрипаль А.В., Пономарев Д.В. // Радиотехника и электроника. 2013. Т. 58. № 11. C. 1071-1076. [Usanov D.A., Skripal' A.V., Ponomarev D.V., Nikitov S.A. // J. Commun. Technol. Electron. 2013. Vol. 58. N 11. P. 1035-1040. DOI: 10.7868/S0033849413110132]

[12] Reynolds A.L., Peschel U., Lederer F., Roberts P.J., Krauss T.F., de Maagt P.J.L. // IEEE Transactions on Microwave Theory and Techniques. October, 2001. Vol. 49. N 10. P. 1860-1867. DOI: 10.1109/22.954799 
[13] Беляев Б.А., Волошин А.С., Шабанов В.Ф. // ДАН. 2005. T. 403. № 3. C. 319-324. [Belyaev B.A., Voloshin A.S., Shabanov V.F. // Dokl. Phys. 2005. Vol. 400. N 1-3. P. 337342. DOI: $10.1134 / 1.2005355]$

[14] Усанов Д.А., Горбатов С.С. Эффекты ближнего поля в электродинамических системах с неоднородностями и их использование в технике СВЧ. Саратов: Изд-во Сарат. унта, 2011. $392 \mathrm{c}$.

[15] Усанов Д.А., Горбатов С.С. // Изв. вузов. Радиоэлектроника. 2006. Т. 49. № 2. C. 27-33. [Usanov D.A., Gorbatov S.S. // Radioelectronics and Communications Systems. 2006. Vol. 49. N 2. C. 1822.]

[16] Стафеев В.И. // ЖТФ. 1958. Т. 28. № 8. С. 1631-1642.

[17] Баранов Л.И., Климов Б.Н., Селищев Г.В. Радиотехника и электроника. 1966. Т. 11. № 8. С. 1441-1446.

[18] Усанов Д.А., Горбатов С.С., Кваско В.Ю., Фадеев А.В., Калямин А.А. // Письма в ЖТФ. 2014. Т. 40. Вып. 21. C. 104-110. [Usanov D.A., Gorbatov S.S., Kvasko V.Yu., Fadeev A.V., Kalyamin A.A. // Tech. Phys. Lett. 2014. Vol. 40. N 11. P. 984-986. DOI: 10.1134/S1063785014110133]

[19] Усанов Д.А., Никитов С.А. Скрипаль А.В., Фролов А.П. // Радиотехника и электроника. 2013. Т. 58. № 12. С. 10711078. [Usanov D.A., Skripal' A.V., Frolov A.P., Nikitov S.A. // J. Commun. Technol. Electron. 2013. Vol. 58. N 12. C. 1130 1136. DOI: $10.7868 / \mathrm{S} 0033849413120176]$ 